\title{
Sistema em Leibniz e Descartes
}

\author{
Celi Hirata ${ }^{1}$
}

\begin{abstract}
RESUMO: Descartes concebe que a verdadeira ordem científica é a ordem das razões, na qual se parte das verdades mais fáceis e evidentes em direção às mais difíceis e complexas. Assim, estabelecese uma ordem única, progressiva e irreversível, onde cada membro da cadeia depende daqueles que o antecederam, de modo que cada tese possui um lugar não-intercambiável dentro da doutrina. Leibniz, ao contrário, defende que "[...] uma mesma verdade pode ter vários lugares, conforme as diferentes relações que pode possuir" (Novos Ensaios, IV, XXI, \4). A fim de evitar as repetições, reunindo-se o máximo de verdades no mínimo de volumes, o autor propõe que a melhor ordem científica é a disposição sistemática das matérias, que consiste em uma organização do saber na qual cada lugar reenvia a outros, tornando clara a conexão entre os conhecimentos. Em contraposição ao modelo de sistema cartesiano, no modelo leibniziano, as teses se fundamentam mutuamente e a ordem das verdades estabelecidas é reversível. Ora, é devido a essas diferenças na concepção de sistema que Leibniz, ao contrário de Descartes, pode pretender tomar o que há de melhor nos sistemas legados pela tradição para constituir o seu próprio sistema, já que para ele há uma certa maleabilidade na constituição do sistema filosófico.
\end{abstract}

PALAVRAS-CHAVE: Ordem das razões. Ordem sistemática. Reversibilidade. Conciliação das filosofias.

No capítulo relativo à divisão das ciências dos Novos Ensaios, FilaletoLocke inicia defendendo que há três grandes espécies de objeto passíveis de serem englobadas pelo entendimento humano: a fisica ou filosofia natural, que diz respeito à natureza das coisas em si mesmas, a moral ou filosofia prática, que trata do homem na qualidade de agente e tem como fim a felicidade, e a lógica, que concerne aos meios de adquirir e comunicar o conhecimento. Dessa forma, a ciência possuiria tal divisão e "[...] essas três espécies, a física, a moral e a lógica, constituem como que três grandes províncias no mundo intelectual, completamente separadas e distintas uma da outra” (NE, IV, XXI, \4, tradução, p. 428). A isso, Leibniz responde que essa divisão, já célebre entre os antigos, apesar de aceitável, possui

\footnotetext{
${ }^{1}$ Doutoranda em Filosofia pelo Departamento de Filosofia da Universidade de São Paulo e bolsista da FAPESP. E-mail: celi_hirata@yahoo.com
} 
um grande problema: “[...] a principal dificuldade existente na divisão proposta das ciências consiste no fato de que cada parte parece engolir o todo" (NE, IV, XXI, p. 428 e 429). Isto é, dentro de cada uma dessas divisões, se os objetos são considerados como é devido, inevitavelmente se recairá numa das outras divisões. Ora, todo o nosso conhecimento, constituído conforme as regras da lógica, simultaneamente concerne à natureza das coisas e está a serviço de nossa felicidade, já que, para Leibniz, o conhecimento é um construto não apenas teórico, como também prático, de modo que se torna complicado definir assim tão estritamente a jurisdição de cada uma dessas divisões. E, para expressar de forma mais contundente o problema que surgiria de uma tal separação entre esses domínios, o filósofo de Hannover utiliza o vocabulário jurídico, pois haveria um conflito de territórios: "[...] com isto tereis as vossas três grandes províncias da enciclopédia em guerra contínua visto que uma se arrogará sempre os direitos das outras" (NE, IV, XXI, p. 429). Por isso, acerca da natureza do conhecimento, ao invés de falar de províncias ou territórios, constitui uma metáfora mais conveniente a do oceano:

Os nominalistas acreditaram que existem tantas ciências particulares quantas são as verdades. Outros comparam o conjunto completo dos nossos conhecimentos a um oceano, que consta todo ele de uma peça única, sendo dividido em caledoniano, atlântico, etiópico e índico, apenas por linhas arbitrárias. Constata-se em geral que uma mesma verdade pode ser colocada em diferentes lugares, conforme os termos que contém, e até conforme os termos médios ou causas de que depende, e segundo as conseqüências ou efeitos que pode produzir [...] Por aí se vê que uma mesma verdade pode ter vários lugares, conforme as diferentes relações que pode possuir. (idem, p. 424, com pequenas modificações na tradução; itálicos meus).

Para Leibniz, com efeito, o que torna inadequada essa separação completa entre física, moral e lógica é que ela, no limite, descura a unidade da verdade, que se mantém una, quer realizemos esta divisão, quer não. Por isso é que o autor da Monadologia cita aqui (pela denominação de "nominalistas") Hobbes, autor que, segundo ele, argumenta que a verdade é arbitrária, já que estaria na dependência das definições, que os homens forjam conforme sua própria conveniência ("Diálogo sobre a conexão entre as coisas e as palavras", GP VII, 191). Ora, como ocorre que uma mesma coisa seja denominada por diferentes nomes (NE, IV, XXI, $\ 4$ ), a verdade seria plural, bem como a ciência, que está na sua dependência, sendo que ela consistiria em várias ciências particulares, sem qualquer unidade verdadeira. Com a metáfora do oceano, que expressa a sua própria posição, Leibniz indica que essas divisões não são consequência da própria natureza do conhecimento, mas sim do nosso arbítrio. Ou seja, dado que a ciência é una, são as nossas divisões que são arbitrárias (não no sentido de que são desprovidas de sentido, mas sim 
no de que somos nós que as realizamos), mas não a verdade, cujo fundamento consiste justamente na proporção entre os caracteres e as coisas, quer dizer, em uma analogia entre a conexão que há entre os elementos de um discurso e a conexão que há entre as coisas que se propõe examinar ("Diálogo...", GP VII, 192). Assim, a fim de classificar as verdades, o mais relevante é pensar nas suas relações ou conexões do que propriamente nessa divisão de objetos, que coloca a natureza de um lado e o homem enquanto agente, de outro.

O que Leibniz quer é mostrar como essa classificação pode possuir um certo sentido, desde que seja entendida não como divisões bem distintas, mas como classificações que correspondem a diferentes ordens que o conhecimento pode ter. Correspondendo à separação tradicional entre física e moral, o filósofo de Hannover salienta que há duas disposições doutrinais principais: uma é sintética e teórica, na qual as verdades são dispostas conforme a origem, isto é, a ordem das provas, de maneira que cada proposição viria depois daquelas das quais depende, o que quer dizer que, nesse caso, progride-se segundo as consequências. Essa ordem é a que corresponde à física. A segunda, que corresponderia à moral, é, inversamente, analítica e prática. Nesta, com efeito, começamos estabelecendo o fim - a felicidade - e procuramos os meios de alcançá-la. Isto é, partimos do efeito desejado para procurar as suas causas ou termos médios de que depende. Aqui, as verdades organizam-se, pois, segundo o uso. Por último, Leibniz adiciona mais uma disposição. Correspondendo à lógica, pode-se dispor o conhecimento conforme os termos, e essa disposição pode ser tanto alfabética quanto sistemática, a saber, segundo os predicados que são comuns a todas as noções (NE, IV, XXI, \4). Ora, cada uma dessas disposições possui o seu mérito, sendo mais ou menos conveniente conforme o enfoque que se quer ter. Assim, Leibniz aceita tal classificação do conhecimento, mas com a condição de que não se pense tratar-se de divisões reais: "[...] esta antiga divisão é muito válida, contanto que seja entendida da forma como acabo de explicar essas disposições, ou seja, não como ciências distintas, mas como disposições diversas das mesmas verdades" (NE, IV, XXI, p. 431)

Enfim, essas disciplinas - física, moral e lógica - tratam das mesmas verdades, sendo que a diferença entre elas consiste na ordem em que o discurso prossegue. Ou seja, elas constituem nada mais do que arranjos diversos das mesmas verdades, de forma que o que é aí decisivo não são as matérias de que se trata, mas o encadeamento delas. Uma vez que para Leibniz as ordens sintética e analítica são recíprocas, diferenciando-se apenas pela ordem empregada no raciocínio (enquanto a primeira parte das noções mais simples em direção às mais compostas, a segunda decompõe as noções mais complexas até alcançar as mais simples), as verdades envolvidas em ambas devem ser as mesmas, ainda que as direções tomadas sejam inversas. Consequentemente, conforme essa divisão, 
haveria uma grande repetição, porque as verdades que se referem a um mesmo objeto se encontrariam catalogadas em diferentes livros.

É importante lembrar que a lamentação pela quantidade excessiva de livros e a apreensão com o seu aumento, motivadas pela invenção da imprensa no fim do século XV, constituíam uma tópica que, inaugurada por Montaigne e expressa por excelência por Descartes, perdurava ainda na época de Leibniz (cf. WILSON, 1989, p. 10-11). De fato, o filósofo de Hannover alerta que o crescimento contínuo dessa "[...] horrível massa de livros" poderia contribuir em muito para o desinteresse e a aversão das pessoas às ciências, fazendo com que os homens recaiam na barbárie (GP VII, 160). Ora, a fim de que o máximo de verdades possa ser exposto no minimo de volumes e que a conexão entre as verdades seja mais intensamente apresentada, talvez seja melhor um outro tipo de disposição do que aquela mencionada acima. A divisão civil das ciências, que se dá segundo as faculdades e as profissões (teologia, jurisprudência, medicina e filosofia) e que Leibniz explicita a seguir, não é de se menosprezar, mas ainda deixa a desejar, porque deixa a encargo da filosofia tudo o que não pode ser incluído nas outras três restantes (NE, IV, XXI, \$4), além de implicar também repetições. "Eis porque a disposição sistemática das matérias é indiscutivelmente a melhor" (idem, p. 432), disposição que consiste em uma organização do saber na qual cada lugar reenvia a outros ("Discours touchant la méthode de la certitude", GP VII, 180), tornando clara a conexão entre conhecimentos antes dispersos e, por isso mesmo, sem os seus devidos frutos. Isto é, na ordem sistemática, os termos são encadeados de forma que um remeta a vários outros, pois a organização aí se orienta pelo o que é comum à pluralidade - dessa maneira, é a disposição mais conforme a natureza da ciência, que é una. Na verdade, é a coesão que mais caracteriza a disposição sistemática e a inspiração de Leibniz a esse respeito distancia-se de Descartes, como se tratará a seguir, aproximando-se muito do estoicismo, de modo que o comentário de Victor Goldschmidt a propósito da concepção estóica de sistema poderia muito bem ser aplicado à própria concepção leibniziana. Nesse sentido, vale a pena reproduzir aqui:

Sistema significa aqui, pois, menos a ordem das razões e o encadeamento das conseqüências aos princípios do que a solidariedade dos dogmas. A qualidade sistemática está menos na conseqüência do que na coesão, menos na sucessão ordenada dos dogmas do que em sua consonância. Dito de outra forma, o sistema é harmonia, muito mais do que continuidade. (GOLDSCHMIDT, 1953, p. 64).

Ora, com base nesse comentário, podemos opor a concepção de sistema leibniziana à cartesiana. Para Descartes, de fato, a ordem verdadeiramente sistemática, isto é, o discurso racionalmente estruturado, constitui-se por meio da disposição das coisas sob a forma de séries, que se orientam não em relação ao 
gênero de seres, conforme as categorias de Aristóteles, mas enquanto umas são conhecidas a partir de outras (Regras para a direção do espirito, VI, p. 31): "[...] a ordem consiste apenas em que as coisas propostas primeiro devem ser conhecidas sem a ajuda das seguintes, e que as seguintes devem ser dispostas de tal forma que sejam demonstradas só pelas coisas que as precedem. E certamente empenhei-me, tanto quanto pude, em seguir esta ordem em minhas Meditações" (Resposta às segundas objeçôes, p. 176). Trata-se de um encadeamento cognitivo das coisas, no qual se apreende por intuição as coisas mais fáceis e imediatas e se prossegue ininterruptamente, por meio de deduções em direção às mais complexas. Ou seja, o sistema cartesiano consiste na disposição do discurso na ordem das razões por oposição à ordem das matérias: enquanto a primeira das ordens procede rigorosamente das verdades mais fáceis às mais difíceis, privilegiando assim a sucessão das provas, a segunda é temática e acondiciona as verdades de acordo com as matérias de que trata, de sorte que, segundo Descartes, as razões permanecem destacadas umas das outras (Carta a Mersenne de 24/12/1640, AT III, 166). A ordem defendida pelo autor das Meditações, ao contrário, é aquela que se realiza por meio de uma cadeia dedutiva constituída no interior de um espírito que raciocina.

Ainda que, para Descartes, essa ordem se aplique à maneira de demonstrar tanto sintética quanto à analítica ${ }^{2}$, ela consiste, com efeito, naquela disposição teórica e sintética descrita por Leibniz, nos Novos Ensaios, que ele afirma ser correspondente à física, na qual as verdades se dispõem conforme a origem, sendo que a validade das proposições posteriores vincula-se à das anteriores. Trata-se, pois, de uma das disposições que o autor da Monadologia vê como um dos arranjos possíveis da verdade. Se, para Leibniz, essa ordem do discurso científico é uma entre outras, para Descartes, ela é a única possivel: segundo o filósofo francês, "[...] todas as coisas possíveis de cair sob o conhecimento dos homens seguem-se umas às outras da mesma maneira" (Discurso do Método, II, p. 46, itálicos meus). Apenas essa disposição é capaz, pois, de produzir certeza no conhecimento, porque o que garante a veracidade do conhecimento é a ordem de sucessão: "[...] como o bloco de certeza constitui-se por meio do encadeamento de verdades segundo a ordem, segue-se daí que nenhuma das verdades da doutrina pode ser interpretada sem referência ao lugar que ela ocupa na ordem" (GUÉROULT, 1953, p. 20, itálico

\footnotetext{
${ }^{2}$ Para Descartes, o modo de escrever dos geômetras envolve dois elementos: a ordem (das razões) e a maneira de demonstrar que, por sua vez, pode ser tanto analítica quanto sintética. Assim, diferentemente de Leibniz, para o filósofo francês, tanto a análise como a síntese seguem a mesma ordem, a saber, do mais fácil ou simples ao mais difícil ou complexo (o que corresponde à ordem sintética em Leibniz), de forma que o que vem depois só pode ser compreendido a partir do que precede. A diferença entre ambas é que, enquanto a síntese é a maneira de demonstrar mais ordinária na geometria, consistindo em "[...] uma longa série de definições, postulados, axiomas, teoremas e problemas", a análise "[...] mostra o verdadeiro caminho pelo qual uma coisa foi metodicamente descoberta", sendo a maneira de demonstrar mais propícia às questões da metafísica (Resposta às segundas objeções, p. 116-117).
} 
meu). Ou seja, enquanto para Leibniz uma mesma verdade pode ter diferentes lugares, de acordo com as diferentes disposições que o discurso incorpora, para Descartes não apenas cada verdade possui um lugar próprio na cadeia dedutiva, como também, mais do que isso, o lugar é constitutivo da verdade: ele é, com efeito, condição mesma de sua validade, já que cada verdade é fundamentada por tudo que lhe antecede. Daí ser a cadeia de deduções irreversivel: as verdades que vêm depois na exposição estão na dependência das que vieram antes, mas não vice-versa. Isto é, a ordem sistemática cartesiana envolve uma desigualdade entre os dogmas, visto que se estabelece uma hierarquia entre o mais fácil e o mais difícil, hierarquia que é expressa pelo distanciamento que um termo possui em relação a outro, no interior da cadeia de intuições e deduções.

Ora, em contraposição a esse modelo de sistema, cujo esquema é o da cadeia ou corrente, a figura que melhor exprime a ordem sistemática leibniziana é, como ressalta Michel Serres, a da rede (SERRES, 1968, p.14). De fato, este autor, comentando a contraposição do filósofo de Hannover tanto a Descartes como a Espinosa, aponta que enquanto estes dois últimos identificaram a coerência ao pensamento dedutivo, Leibniz teve "[...] consciência desta liberdade na composição das vias da determinação racional", sendo que seu sistema constitui-se como um "conjunto ordenado e multilinear de encadeamentos cruzados" e caracteriza-se "[...] por esta possibilidade de retornos múltiplos", de modo que aí se constituem dois temas principais: "continuidade e reversibilidade" (SERRES, 1968, p. 12, 28 e 70). Assim, a coerência no sistema leibniziano fundamenta-se em uma certa simultaneidade, ou melhor, como no estoicismo, não propriamente na hierarquia, mas na solidariedade dos dogmas: cada parte reenvia igualmente a todas as demais, ao todo, de forma que a sucessão é apenas uma das ordens que se pode percorrer - na ordem sistemática, deve haver muitas remissões de uma parte a outra, "[...] a maioria das coisas podendo ser observadas de uma pluralidade de lados ou aspectos" ("Discours...", GP VII, 180). Afinal, as mesmas verdades podem ter diversos arranjos; elas não precisam estar expostas em uma cadeia dedutiva para assegurar sua validade. Ora, por ter uma concepção de coerência discursiva que não só permite como exige enquanto requisito a reversibilidade, característica proveniente da fundamentação mútua das partes, a ordem sistemática leibniziana detém uma certa maleabilidade, porque, se, na concepção de Descartes, só pode haver um único caminho possível para se chegar às verdades - caminho que precisa ser constituído desde o início por cada sujeito cognoscente e no qual cada um dos dogmas possui um lugar próprio e não-intercambiável na cadeia , para Leibniz, os caminhos possíveis são múltiplos, uma vez que a disposição das verdades segundo a origem e a sucessão não é a única. Daí ele poder defender a possibilidade de que teorias provenientes de origens distintas, quer dizer, de 
diferentes doutrinas, possam ser em princípio retomadas, conciliadas e arranjadas em um sistema seu.

Descartes, ao contrário, não pode aceitar uma tal possibilidade. Para esse autor, como é sabido, a diversidade das doutrinas a respeito de um mesmo assunto é índice da falsidade de todas, visto que a verdade é evidente, compelindo todos os espíritos a tomá-la como tal (Discurso do método, I, p. 40). Ademais, mesmo se as doutrinas existentes fossem verdadeiras, subsistiria uma outra dificuldade: a questão da transmissibilidade do conhecimento. Com efeito, de acordo com o filósofo francês, um espírito só pode conceber bem uma coisa quando ele mesmo inventa, de modo que não se pode aprender qualquer doutrina de outrem, por melhor que ela seja explicada (Discurso do método, VI, p. 75). Assim, como não nos tornamos matemáticos sabendo de cor as demonstrações realizadas por outros, não nos transformamos em filósofos lendo os raciocínios empreendidos por Platão ou Aristóteles: de tal modo se aprende apenas história, mas jamais ciência (Regras para a direção do espírito, III, p. 18 e 19). Por essa razão, se Descartes se preocupa em ensinar - essa é uma das vantagens alegadas por ele da via analítica, que, mostrando o caminho pelo qual uma coisa foi metodicamente descoberta, é mais propícia ao ensino (Resposta às segundas objeções, p. 176 e 177) -, é porque ele acredita poder apontar a ordem metódica pela qual as verdades são rigorosamente estabelecidas, mesmo se ele, para cumprir a retórica da modéstia, diga que não tem a pretensão de ensinar o método que cada um deve utilizar para bem conduzir a sua razão (Discurso do método, I, p. 38). Mais do que dogmas, o que ele pretende é instituir um método, método que ele expõe nas Meditações e no Discurso do Método, por meio das cadeias de verdade que ele descobriu e nas Regras para a direção do espírito em forma de regras. Em decorrência, seria possível afirmar que Descartes é em certa medida um precursor da afirmação kantiana de que não se aprende a filosofia, mas sim a filosofar. ${ }^{3}$ Isto é: pode-se aprender e seguir o método, que justamente consiste em um caminho "[...] para bem conduzir a própria razão e procurar a verdade nas ciências", todavia, não se pode aprender um sistema de filosofia, já que não se pode conceber bem a doutrina que um outro estabeleceu, pois cada

\footnotetext{
3 Vale a pena citar também o que Kant escreveu, no parágrafo anterior a essa afirmação: “[...] por isso aquele que aprendeu especialmente um sistema de filosofia, por exemplo o de Wolff, mesmo que tivesse na cabeça todos os princípios, explicações e demonstrações, assim como a divisão de toda a doutrina e pudesse, de certa maneira, contar todas as partes desse sistema pelos dedos, não tem senão um conhecimento bistórico completo da filosofia wolffiana. Sabe e ajuíza segundo o que the foi dado. Contestais-lhe uma definição e ele não sabe onde buscar outra. Formou-se segundo uma razão alheia, mas a faculdade de imitar não é a faculdade de invenção, isto é, o conhecimento não resultou nele da razão e embora seja, sem dúvida, objetivamente, um conhecimento racional, é, contudo, subjetivamente apenas histórico [...] Entre todas as ciências racionais (a priori) só é possível, por conseguinte, aprender a matemática, mas nunca a filosofia (a não ser historicamente): quanto ao que respeita à razão, apenas se pode, no máximo, aprender a filosofar" (Crítica da Razão Pura, B 864-865, p. 659-660).
} 
um precisa reconstituir por si mesmo a cadeia de razões: ensina-se o caminho, mas para ver o que há ao longo deste, cada um deve caminhar com suas próprias pernas, porque as coisas a serem observadas estão diretamente relacionadas à distância percorrida. Assim, para Descartes, não se pode aprender as verdades que um outro espírito obteve por meio de seus raciocínios, visto que é a própria ordem em que as proposições estão dispostas que as valida como verdadeiras, de forma que o que não está fundamentado nas razões anteriormente concebidas pelo próprio espírito deve ser considerado duvidoso e, consequentemente, de acordo com o método cartesiano, falso.

Enfim, se para Descartes o conhecimento só é genuíno se desenvolvido pela própria pessoa, pois, para aquele que deseja efetivamente conhecer, há um caminho determinado de verdades que ele precisa inevitavelmente trilhar para chegar a algum saber, para Leibniz, devido à pluralidade de vias possíveis no conhecimento, torna-se possível o rearranjo das verdades sob um novo sistema. Assim, a correlação entre inventário e invenção, isto é, entre a reunião e catalogação das melhores doutrinas existentes e o avanço do conhecimento, que, na perspectiva da filosofia cartesiana, não faz sentido, porque, para o autor das Meditaçôes, a erudição ou instrução pelo pensamento alheio não se liga à descoberta de verdades, viabiliza-se em Leibniz como trabalho de organização do discurso. Ou seja: a retomada dos melhores dogmas e teses estabelecidos pelos sábios com vista ao aumento e ao aperfeiçoamento do conhecimento humano dá-se mediante o rearranjo deles em um sistema novo, no qual a conexão entre as verdades seja tornada clara. A conciliação do que há de melhor nas filosofias que Leibniz pretende repousa, pois, em um trabalho de organização, como Adelino Cardoso comenta: "[...] o trabalho de compatibilização das verdades é um trabalho que consiste em estabelecer correspondências por intermédio de sua ordenação mútua" (CARDOSO, 1992, p. 23). Ou seja, trata-se de sistematizar as melhores teses, o quer dizer organizá-las em um todo no qual cada parte reenvia às demais. Assim, o que Leibniz busca é coordenar a pluralidade dos dogmas pelos princípios diretores do sistema, tais como o do melhor, o da continuidade e o da identidade dos indiscerníveis, de modo que o que ele retomou de outras doutrinas se integre em seu próprio sistema.

Ora, a concepção de que a unidade do que é verdadeiro se mantém sob a diversidade das disposições correlaciona-se não apenas com essa possibilidade de constituir um sistema que concilia os melhores aspectos de outros sistemas como também com a possibilidade de reversibilidade das partes da doutrina, no interior do próprio sistema: como as verdades podem assumir lugares diferentes conforme as relações e ênfases que se quer estabelecer, os dogmas podem adquirir diferentes posições em cada texto, sem que a coerência e a unidade se percam, 
que, ao contrário, são tão fortes que se mantêm sob as variações de ordem. De fato, é isso que pode ser observado na obra de Leibniz, principalmente quando se pensa nos seus textos mais importantes: no Discurso de Metafísica, o autor começa pela consideração da Divindade e de suas perfeições; na Monadologia, ele inicia o discurso apresentando as substâncias simples que povoam o mundo; no Novo sistema da natureza, ele expõe, como nas Meditações de Descartes, de uma maneira autobiográfica, motivado pelo problema da união da alma com o corpo, suas descobertas acerca da noção de força e de outras noções; nos Novos Ensaios, enfim, ele pode apresentar a sua própria doutrina conforme a ordem da exposição de um outro autor. Em todas essas obras, são afirmados, com pequenas variações, os mesmos dogmas, porém, em ordens diferentes. Isto é, não existe um começo absoluto no discurso científico, o que importa é a universalidade das regras estabelecidas, que é o que afinal define a sistematicidade para Leibniz. Assim, segundo o autor, nada enfraquece mais um determinado corpo de doutrina do que a vacilação e a grande quantidade de exceções (Teodiceia, \44, GP VI, 127).

O filósofo de Hannover opõe-se, dessa forma, ao modelo euclidiano de sistematização, no qual há um pequeno número de teses fundamentais que são tidas como indemonstráveis e a partir das quais todo o restante da doutrina deve ser derivado sequencialmente, por meio de deduções. Neste, há uma base finita de elementos (os axiomas e as definições) e de processos dedutivos. O modelo leibniziano de sistema, ao contrário, não se inspira na geometria grega, mas na física do século XVII, mais exatamente no cálculo de variações, pelo qual o máximo de conteúdo é organizado pelo mínimo de princípios operativos (RESCHER, 1981, p. 122). A unidade do conhecimento deixa, assim, de residir na unidade do processo dedutivo para ser assegurada pela universalidade dos princípios empregados, unidade que se mantém sob a diversidade das exposições. Tal como o mundo, que concentra o máximo de realidade com o máximo de ordem e de economia, no qual a maior variedade possível de fenômenos é originada com base no mínimo de decretos e o máximo de seres coexiste em harmonia, a filosofia de Leibniz possui inúmeras exposições (que, vale dizer, são tantas a ponto de não estarem completamente editadas até hoje), sem que a unidade das doutrinas e dos princípios seja perdida.

De fato, enquanto, em Descartes, o discurso científico possui uma ordem própria, um encadeamento que depende da maneira como nós apreendemos cognitivamente as coisas (ordem das razões), que se distingue da relação de dependência que há entre as próprias coisas, em Leibniz, há uma consonância entre a ordem da realidade e da teoria. Afinal, como já se disse, o fundamento da verdade reside na correlação regrada entre as palavras e as coisas, de modo que, para o autor da Monadologia, a concepção de sistema engloba tanto a realidade como o 
discurso: a solidariedade dos dogmas na teoria corresponde à solidariedade entre as coisas no universo, isto é, à harmonia. Por isso, o mundo atual é ao que se aplica por excelência o vocábulo "sistema": trata-se do "[...] melhor dos sistemas possíveis" (por ex., carta de Leibniz a Bourguet, GP III, 578 e Theodicée, GP VI, p. 273), o que quer dizer a totalidade na qual o mínimo de regras produz o máximo de efeitos. E o melhor sistema explicativo da relação entre os seres criados, sistema que se sobressai ao do influxo causal e ao do ocasionalismo, é o sistema da harmonia preestabelecida, que, supondo o mínimo de decretos, dá conta da maneira mais regrada e universal dos fenômenos observáveis (por ex., GP VI 546 e 595). ${ }^{4} \mathrm{Da}$ mesma forma que, no mundo, a multiplicidade é conciliada com a simplicidade, na medida em que todos os seres criados percebem e exprimem os mesmos fenômenos, mas a partir de diferentes perspectivas, o que resulta em graus diferentes de distinção (por ex., Discurso de Metafísica, \9, p. 18; Monadologia, \$60-62, p. 142-3), o sistema leibniziano, apesar de ser apresentado em exposições diferentes, é uno e coeso. Assim, comentando o seu próprio sistema, o autor afirma: "[...] encontro nele uma simplicidade e uma uniformidade surpreendentes, de modo que se pode dizer que é em toda parte e sempre a mesma coisa, com exceção dos graus de perfeição" (NE, Prefácio, p. 28).

A verdade não é relativa: ela não pode valer para alguns casos e para outros não. Por isso é que Leibniz terá em conta, em cada parte de seu sistema, a totalidade do real: "[...] entre as vantagens do meu sistema (está) aquela da universalidade das regras que eu emprego, que são sempre sem exceção na minha filosofia geral" (“Considérations sur les principes de vie", GP VI, 545). Além disso, não só cada parte do sistema deve ter como horizonte o todo da realidade, como também cada região do sistema deve relacionar-se com a totalidade da doutrina: "[...] não se pode destacar nada no meu sistema, pois há em tudo uma perfeita conexão" (Die Leibniz-Handschriften, p. 58). Serres, comentando essa característica do sistema leibniziano segundo o modelo matemático da função, sublinha que, "[...] no limite, esta ciência projeta sua totalidade distributiva em cada ponto distinto da meditação filosófica" (SERRES, 1968, p. 219) Isto é, no sistema de Leibniz, cada parte é expressiva da totalidade. Em função disso, o filósofo, em muitos de seus textos, imbrica as três divisões da ciência proposta por Locke, física, moral e lógica, através de formulações densas que, com poucas palavras, visam a dar conta de vários problemas filosóficos importantes.

\footnotetext{
${ }^{4}$ Nicholas Rescher chama a atenção para o fato de que, apesar da ideia que subjaz ao que denominamos hoje "sistema" remonte à Antiguidade, Leibniz foi o primeiro da história a utilizar o termo para designar uma doutrina articulada num complexo organizado de hipóteses concordantes e a descrever a si mesmo como possuindo um sistema de filosofia (cf. RESCHER, 1981).
} 
Enfim, se tanto Leibniz como Descartes enfatizam, por um lado, que o conhecimento não deve ser organizado e exposto tematicamente, de acordo com as matérias ou divisão dos objetos, mas sim em função da conexão que os conhecimentos possuem entre si, sendo que a unidade da ciência é assegurada por essa conexão mesma, ambos possuem, por outro, concepções bem distintas de sistema filosófico, o que acarreta em métodos e projetos diferentes de produção de conhecimento. Para Descartes, a conexão entre os conhecimentos só pode ser de um tipo, a saber, dedutiva, pela qual se estabelece uma ordem hierárquica e irreversível entre os dogmas, sendo cada verdade justificada por aquelas que a antecederam. Trata-se de uma ordem estritamente cognitiva, que deve ser seguida por cada um que queira meditar. Ora, a partir dessa concepção, tornase, pelo menos de direito, inviável a retomada de teses provenientes de outros sistemas filosóficos, já que estas permaneceriam necessariamente injustificadas. Já Leibniz possui uma compreensão muito mais ampla de sistema filosófico, de sorte que a concepção cartesiana de ordem figura aí como uma dentre as múltiplas possíveis. Tal como o mundo, no qual cada ser, cada fenômeno, remete a todos os demais de múltiplas maneiras, constituindo o sistema por excelência, na ordem sistemática do conhecimento subsistem várias conexões entre os dogmas, de forma que há várias ordens possíveis de exposição das teses. Respeitando a concepção segundo a qual o fundamento da verdade reside na proporção entre os caracteres e as coisas, quer dizer, entre o discurso e a realidade, o sistema, entanto doutrina articulada, expressa o sistema do mundo, sistema que se caracteriza pela harmonia, isto é, pela existência da unidade na multiplicidade. Ora, visto que, para Leibniz, a ordem sistemática permite diversos arranjos possíveis, de modo que as teses não precisam estar inseridas numa ordem dedutiva, progressiva e irreversível para serem válidas, torna-se possível o rearranjo das melhores teses dos sistemas legados pela tradição no seu próprio sistema, que, aos olhos de seu autor, acaba por se tornar o sistema dos sistemas - comentando a sua própria obra, na pele de Teófilo dos Novos Ensaios, Leibniz afirma: “[...] este sistema parece aliar Platão com Demócrito, Aristóteles com Descartes, os escolásticos com os modernos, a teologia e a moral com a razão. Parece que ele toma o que há de melhor de todos os lados, e que depois vai mais longe do que se tem ido até hoje" (NE, I, I, p. 28). 
HIRATA, Celi. System in Leibniz and Descartes. Trans/Form/Ação, Marília, v. 35, n. 1, p. 23-36, Jan./Abril, 2012.

\begin{abstract}
Descartes thinks that the true scientific order is that of reasons, in which one starts from the easiest and most evident truths and moves towards those that are more difficult and complex. Thus a unique, progressive, and irreversible order is established, where each member of the chain depends on those that precede it, and each thesis has a non-interchangeable place inside the doctrine. Leibniz, on the contrary, defends the idea that "une même vérité peut avoir beaucoup des places selon les differents rapports qu'elle peut avoir" (Nowveaux Essais, IV, XXI, \4 ; GP V, p. 506). In order to avoid repetition, assembling the greatest quantity of truths in a minimum of volumes, Leibniz argues that the best scientific order is a systematic disposition in which each place refers to all the others, so that the connections among knowledge becomes clear. In opposition to the Cartesian model of system, in the Leibnizian model theses are based upon one another, and the order of truths is reversible. It is due to these differences concerning the conception of system that Leibniz, unlike Descartes, can pretend to take the best of each philosophical system in order to constitute his own, given that for him there is a certain malleability in the construction of a philosophical system.
\end{abstract}

KEYWORDS: order of reasons; systematic order; reversibility; conciliation of philosophies.

\title{
REFERÊNCIAS
}

CARDOSO, Adelino. Leibniz segundo a expressão. Lisboa: Colibri, 1992.

DESCARTES, René. Discurso do Método. São Paulo: Abril, 1973 (Coleção Pensadores). . Meditações. São Paulo: Abril, 1973 (Coleção Pensadores). . Resposta às segundas objeções. São Paulo: Abril, 1973 (Coleção Pensadores). . Regras para a direção do espírito. Tradução: Maria Ermantina Galvão.São Paulo: Martins Fontes, 1999.

Carta a Meresenne de 24/12/1640. In: ADAM, C.; TANNERY, P. (Ed.). CEvres de Descartes, volume III. Paris: Vrin, 1989.

GOLDSCHMIDT, Victor. Le système stö̈ien et l'idée de temps. Paris: Vrin, 1953.

GUÉROULT, Martial. Descartes selon l'ordre des raisons, volume I. Paris: Aubier, 1953.

KANT, Immanuel. Crítica da Razãa Pura. Tradução: Manuela Pinto dos Santos e Alexandre Fradique Morujão. Lisboa: Calouste Gulbenkian, 1997.

LEIBNIZ, Gottfried Wilhelm. Novos Ensaios. Tradução: Luiz João Baraúna. São Paulo: Abril, 1980 (Coleção Pensadores, volume XIX.

GERHARDT, C. (Ed.). Die Philosophischen Schriften von Gottfried Wilhelm Leibniz, volumes III, VI e VII. Berlim: Georg Olms Hildesheim,1960. 
BODEMANN, E. (Ed.). Die Leibniz-Handschriften der Königlichen öffentlichen Bibliothek zu Hannover. Hannover: Georg Olms Hildesheim, 1966.

Discurso de Metafísica. In: Discurso de metafísica e outros textos. Tradução: Marilena Chaui e Alexandre da Cruz Bonilha. São Paulo: Martins Fontes, 2004.

. Monadologia. In: Discurso de metafísica e outros textos. Tradução: Marilena Chaui e Alexandre da Cruz Bonilha. São Paulo: Martins Fontes, 2004.

RESCHER, Nicholas. Leibniz and the concept of a system. Studia Leibnitiana, $\mathrm{n}^{\circ} 13$, , p. 114-122, 1981.

SERRES, Michel. Le système de Leibniz, et ses modeles mathématiques, primeiro volume. Paris: PUF, 1968.

WILSON, Catherine. Leibniz's metaphysics: a historical and comparative study. New Jersey: Princeton University Press, 1989.

Recebido em: 15.09.2011

Aprovado em: 10.11.2011 
HIRATA, $C$. 